\title{
Heterogeneous Microstructures of Spherulites of Lipid Mixtures Characterized with Synchrotron Radiation Microbeam X-ray Diffraction
}

\author{
Laura Bayés-García, ${ }^{* a}$ Teresa Calvet, ${ }^{a}$ Miquel Àngel Cuevas-Diarter ${ }^{a}$ Satoru Ueno ${ }^{b}$ and Kiyotaka Sato ${ }^{b}$
}

\author{
${ }_{5}$ Received (in $\left.X X X, X X X\right)$ Xth $X X X X X X X X X 20 X X$, Accepted Xth $X X X X X X X X X 20 X X$ \\ DOI: $10.1039 / b 000000 x$
}

\begin{abstract}
We observed microstructures of spherulites made of two triacylglycerols (TAGs) (POP (1,3dipalmitoyl-2-oleoyl-sn-glycerol) and OPO (1,3-dioleoyl-2-palmitoyl-sn-glycerol)), which exhibit the mixing behavior of a molecular compound (MC) formation at a ratio of POP:OPO $=50: 50$, 10 using synchrotron radiation microbeam (beam area of $5 \times 5 \mu \mathrm{m}^{2}$ ) X-ray diffraction (SR- $\mu$-XRD). The spherulites were grown from neat liquid, and from solution containing 50\% n-dodecane and 50\% POP+OPO. SR- $\mu$-XRD analysis revealed heterogeneous distributions of MCPOP:OPO and component TAGs in every spherulite; TAG compositions in the inner and outer areas differed when the relative ratios of POP and OPO were changed. In the 75POP:25OPO spherulites, MCPOP:OPO always 15 occupied the inner areas and POP dominated the outer areas as a result of different rates of crystallization of $\mathrm{MC}_{\mathrm{POP}: \mathrm{OPO}}$ and POP in the spherulite. In contrast, in the 25POP:75OPO spherulites, the entire area was homogeneously occupied either with almost all OPO or with coexisting $\mathrm{MC}_{\mathrm{POP}: \mathrm{OPO}}$ and $\mathrm{OPO}$. The microstructures of the spherulites grown from n-dodecane solutions demonstrated basically the same characteristics as those grown from the neat liquid both 20 for 75POP:25OPO and 25POP:75OPO. SR- $\mu$-XRD also clarified that the lamellar planes of the crystals are directed parallel to the radial direction from the central to the outer regions of the spherulites.
\end{abstract}

\section{Introduction}

Lipids are major nutrients, along with proteins and 25 carbohydrates, and are employed as lipophilic materials in food, cosmetic, and pharmaceutical industries. ${ }^{1}$ Many lipids, such as triacylglycerols (TAGs) and diacylglycerols (DAGs), consist of multiple components in two ways: (i) a lipid phase contains a variety of lipids differing in hydrophilic and 30 hydrophobic structures, and (ii) each single lipid molecule involves different types of fatty acid moieties. Therefore, the physicochemical properties of lipids must be studied not only in their pure systems but also in mixed systems. In particular, studies on binary mixture systems provide valuable 35 information about molecular interactions among different lipid materials. The same analysis is applied to TAGs, which are the main components of natural and industrial lipids.

Diversified molecular interactions among TAGs are found in polymorphism and mixing behavior. Multiple polymorphic 40 forms occur in almost all TAGs. The number of individual polymorphic forms and their molecular structures drastically change when fatty acid compositions included in the TAGs are changed. ${ }^{1}$ Moreover, for the binary mixing behavior of TAGs, three phases have been confirmed: (i) solid solution
${ }_{45}$ phase, (ii) eutectic phase, and (iii) molecular compound (MC) formation phase. When two component TAG molecules exhibit structural similarity and affinitive molecular interactions, a miscible solid solution phase is formed. However, when two component molecules are immiscible due 50 to steric hindrance, the eutectic phase is formed. ${ }^{1-3}$ An example of immiscible mixing systems is the formation of $\mathrm{MC}$ phase, which is formed through specific molecular interactions between two component molecules. ${ }^{4}$

The properties of polymorphism and mixing behavior of 55 TAGs are strongly related because the chemical nature (saturated or unsaturated) of the component TAG molecules results in complicated polymorphism and mixing behavior. For instance, referring to the chemical nature and the unsaturation effect in monoacylglycerols ${ }^{5}$, Kulkarni et al. ${ }^{6}$ ${ }_{60}$ examined the influence of manipulating double bonds in the phase behavior and the number density of channels in inverse bicontinuous cubic phases. As to lipid mixtures systems, Seddon et al. ${ }^{7}$ studied the phase behavior of saturated diacyl phosphatidylcholine/fatty acid mixtures with different chain ${ }_{65}$ lenghts as a function of water content. Later, Templer et al. ${ }^{8}$ focused on the inverse cubic phases obtained when the phosphatidylcholine was mixed with fatty acids in water and observed that there was no formation of these phases for long 
Table 1 Polymorphic structures of POP and OPO grown from neat liquid

\begin{tabular}{|c|c|c|c|c|}
\hline TAGs & Polymorphs & $\mathrm{T}_{\mathrm{m}}\left({ }^{\circ} \mathrm{C}\right)^{a}$ & Chain length structure & Long spacing value (nm) \\
\hline $\mathrm{POP}^{21}$ & $\begin{array}{l}\alpha \\
\gamma \\
\beta^{\prime}{ }_{2} \\
\beta{ }_{1} \\
\beta_{2} \\
\beta_{1}\end{array}$ & $\begin{array}{l}15.2 \\
27.0 \\
30.3 \\
33.5 \\
35.1 \\
36.7\end{array}$ & $\begin{array}{l}\text { Double } \\
\text { Triple } \\
\text { Double } \\
\text { Double } \\
\text { Triple } \\
\text { Triple }\end{array}$ & $\begin{array}{l}4.7 \\
6.5 \\
4.2 \\
4.2 \\
6.1 \\
6.1\end{array}$ \\
\hline $\mathrm{OPO}^{13}$ & $\begin{array}{l}\alpha \\
\beta^{\prime} \\
\beta_{2} \\
\beta_{1}\end{array}$ & $\begin{array}{c}-18.3 \\
11.7 \\
15.8 \\
21.9\end{array}$ & $\begin{array}{c}\text { Double } \\
\text { Double } \\
\text { n. d. } \\
\text { Triple }\end{array}$ & $\begin{array}{l}4.8 \\
4.4 \\
5.6 \\
6.4\end{array}$ \\
\hline $\mathrm{MC}_{\mathrm{POP} / \mathrm{OPO}}{ }^{13}$ & $\begin{array}{l}\alpha \\
\beta\end{array}$ & $\begin{array}{l}\text { n.d }{ }^{b} \\
32.0\end{array}$ & $\begin{array}{l}\text { Double } \\
\text { Double }\end{array}$ & $\begin{array}{l}4.7 \\
4.2\end{array}$ \\
\hline
\end{tabular}

(a)

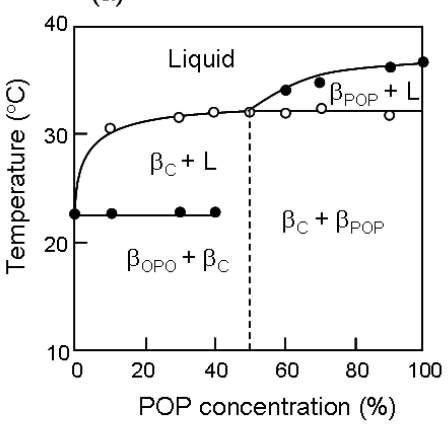

(b)

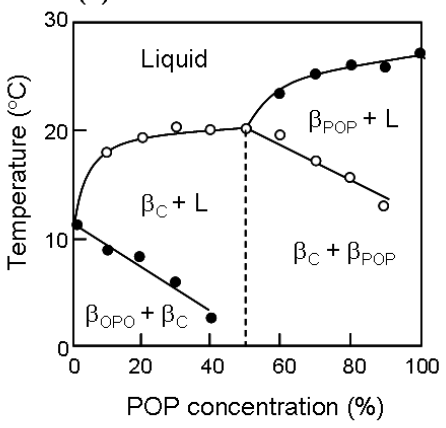

POP

(c)

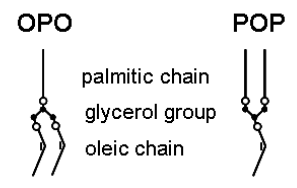

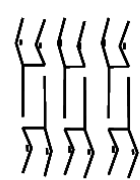

$\beta_{\mathrm{OPO}}-3$

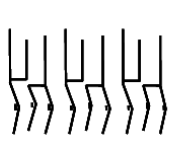

$\beta_{\mathrm{C}}-2$

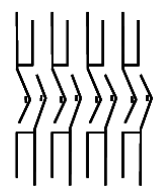

$\beta_{\mathrm{POP}}-3$

Fig. 1 Phase behaviour of POP:OPO mixtures. (a) Neat liquid. (b) In 50\% solution of n-dodecane. (c) Model of the $\beta_{\mathrm{MC}}$ (double chain length structure) 30 compared to $\beta_{\mathrm{POP}}$ and $\beta_{\mathrm{OPO}}$ (triple chain length structure).

chain fatty acids.

As typical examples, we present here TAGs containing palmitic and oleic acid moieties, PPP (tripalmitoyl glycerol), ${ }_{35}$ OOO (trioleoyl glycerol), POP (1,3-dipalmitoyl-2-oleoyl glycerol), OOP (1,2-dioleoyl-3-palmitoyl glycerol), PPO (1,2dipalmitoyl-3-oleoyl glycerol), and OPO (1,3-dioleoyl-2- palmitoyl glycerol). The mixtures of $\mathrm{PPP}+\mathrm{POP}^{9}, \mathrm{PPP}+\mathrm{OOO}^{10}$, and $\mathrm{POP}+\mathrm{OOP}^{11}$ are eutectic, whereas the mixtures of ${ }_{40} \mathrm{POP}+\mathrm{PPO}$ and $\mathrm{POP}+\mathrm{OPO}$ are $\mathrm{MC}$-forming at ratios of POP:PPO = 50:50 and POP:OPO $=50: 50 .{ }^{12,13}$ The MCforming mixtures of $\mathrm{POP}+\mathrm{OPO}$ were observed in crystals formed not only from neat liquid, but also from solutions 
including $\mathrm{n}$-dodecane as a solvent ${ }^{14}$, as this binary mixture is significant for fractionation of palm oil in dry and solvent methods.

Currently, most research on the binary mixing behavior of 5 TAGs has been conducted on a thermodynamic equilibrium phase diagram. However, crystallization behavior is significant for applications: for example, fractionation of palm oil to produce high-melting, medium-melting, and lowmelting fractions for multiple applications is influenced by 10 crystallization properties of high-melting fractions such as PPP, POP, PPO, OOP, and OPO. ${ }^{15}$ This property is related to kinetic aspects of the binary mixing systems. However, few studies of kinetic properties of TAG mixtures have been conducted.

15 In the present study, we seek to analyze the microstructures of spherulites of the mixtures of POP and OPO formed from neat liquid and solution including $\mathrm{n}$-dodecane. Spherulites are the most typical crystal morphology of TAGs during cooling from neat liquid and solution. ${ }^{16}$ Instead of growth of single 20 crystal pieces separately, fat crystals tend to grow in the form of spherulites at ambient temperatures and moderate cooling rates. ${ }^{17,} 18$ The morphology and microstructures of spherulites are determined by crystallization kinetics, since the central region of a spherulite is formed by the nucleation of many 25 tiny crystals, and post-nucleation crystal growth occurs toward the external region. Thus, the microstructures of the spherulites of the mixture samples are determined by relative rates of nucleation and crystal growth of component materials. Therefore, detailed analysis of microstructures of spherulites 30 provides deep insight into crystallization kinetics of longchain soft materials, as reported in polymer $^{19}$ and TAG crystals. ${ }^{20}$

Our particular concern in this work was to examine how the microstructures of spherulites of the TAG mixtures are 35 determined, when the MC crystals and POP or OPO component crystal can be formed competitively. The polymorphic structures of POP, OPO, and MCPOP:OPO are summarized in Table 1 . Figure 1 depicts phase diagrams of POP+OPO mixtures in neat liquid (Fig. 1a) ${ }^{13}$ and n-dodecane $40(50 \%)$ solution (Fig. 1(b)). ${ }^{14}$ At a concentration ratio of POP:OPO $=75: 25$, POP and МCPOP:OPO are formed at an equal ratio; at a concentration ratio of POP:OPO $=25: 75$, MCPOP:OPO and OPO are formed at an equal ratio. The molecular structures of POP, OPO, and MCPOP:OPO are largely ${ }_{45}$ different, as seen in the triple-chain-length structures of POP and $\mathrm{OPO}$, and the double-chain-length structure of $\mathrm{MC}$ POP:OPO (Fig. 1c). Thus, observation of microstructures of spherulites may provide information about the relative crystallization rates of $\mathrm{MC}_{\mathrm{POP}: \mathrm{OPO}} \mathrm{POP}$, and $\mathrm{OPO}$. For this purpose, we 50 employed synchrotron radiation microbeam X-ray diffraction (SR- $\mu$-XRD).

The principle of SR- $\mu$-XRD relies on X-ray focusing optics and a synchrotron radiation $\mathrm{X}$-ray source, and it enables scanning in two dimensions of the sample, with steps on the 55 order of the beam size. SR- $\mu$-XRD has been used to examine many soft materials (e.g., biological tissues, ${ }^{22-31}$ starch, ${ }^{32}$ proteins, and synthetic polymers $\left.{ }^{19}, 33-35\right)$. For example, Kajiura et al. ${ }^{28}$ studied the keratin fibre arrangement of different types of human hair by $S R-\mu-X R D$ to determine the origin of 60 curliness. Also, Seidel et al. ${ }^{30}$ studied the orientation of chitin fibres of the airflow sensors of crickets. SR- $\mu$-XRD analysis of spherulites revealed different types of microstructures on a micrometer scale, which traditional diffraction techniques had not detected. ${ }^{36}$

${ }_{65}$ Our group was the first to apply SR- $\mu$-XRD to lipid samples, such as spherulite of trilaurin, ${ }^{20}$ oil-in-water emulsion, ${ }^{37,}, 38$ and granular crystals of palm-oil-based waterin-emulsion. ${ }^{39}$ SR- $\mu$-XRD analysis of trilaurin spherulites indicated that the lamellar planes of tiny crystals are aligned 70 parallel to the radial direction from the central and peripheral directions of the spherulite. Furthermore, the same study showed that the lamellar directions are not randomized after solid-state polymorphic transformation from $\beta$ ' to $\beta$ forms.

In the present work, scanning SR- $\mu$-XRD experiments of 75 spherulites of the binary mixtures of POP and OPO clarified the details of heterogeneous structures.

\section{Experimental}

Samples of POP and OPO (purity $>99 \%$ ) were purchased from Tsukishima Foods Industry (Tokyo, Japan) and used without 80 further purification. The solvent, n-dodecane (99\% pure), was purchased from Nakalai Tesque (Kyoto, Japan). To prepare the binary mixtures of OPO and POP (wt\%), two TAG samples were melted at $50^{\circ} \mathrm{C}$ and mixed using a vortex. When $\mathrm{n}$-dodecane was added to the POP+OPO mixtures, the ratio of $85 \mathrm{n}$-dodecane/(POP+OPO) was $1 / 1$ (50\% solution).

The SR- $\mu$-XRD experiments were carried out at beamline BL-4A of the synchrotron radiation facility Photon Factory (PF) at the High-Energy Accelerator Research Organization (KEK) in Tsukuba, Japan. The details of the experiment set90 up are reported elsewhere ${ }^{20}$ (see Supplementary Text in the Electronic Supplementary Information). The X-ray microbeam wavelength was $0.11 \mathrm{~nm}$, and the beam area was $5 \mathrm{x} 5 \mu \mathrm{m}^{2}$. The sample was moved by an $x-y-z$ stepping motor ( $1 \mu \mathrm{m}$ step) while being observed by an optical microscope. The X-ray 95 data was detected by a CCD camera to produce twodimensional (2D) patterns. Basically, it is possible to observe small-angle and wide-angle diffraction patterns simultaneously in the SR- $\mu$-XRD experiments, as examined in $\mathrm{O} / \mathrm{W}$ emulsion. ${ }^{37}$ In the present study, however, we focused on 100 only small-angle SR- $\mu$-XRD patterns, so that diffraction peaks corresponding to long spacing values (lamellar distances) could be observed with high resolution by expanding the $2 \mathrm{D}$ patterns at the small diffraction angle regions.

In order to determine the temperature at which spherulites 105 that were large enough to be examined with the SR- $\mu$-XRD were grown, crystallization experiments were performed using a Linkam LK-600 PM stage (Tadworth, UK) mounted on an Olympus BX51 microscope (Tokyo, Japan). The system also consisted of an LNP liquid nitrogen cooling system and an L${ }_{110} 600 \mathrm{~A}$ temperature controller. Optical micrograph images were taken with an Olympus DP12 Digital Camera.

After determining the optimal crystallization conditions, we prepared spherulites for the SR- $\mu$-XRD experiments by the following process. A sample of molten mixture was placed 
Table 2 Melting temperatures $\left(\mathrm{T}_{\mathrm{m}},{ }^{\circ} \mathrm{C}\right)$, crystallization temperatures $\left(\mathrm{T}_{\mathrm{c}},{ }^{\circ} \mathrm{C}\right)$ and supercooling values $\left(\Delta \mathrm{T}=\mathrm{T}_{\mathrm{m}}-\mathrm{T}_{\mathrm{c}},{ }^{\circ} \mathrm{C}\right)$

\begin{tabular}{ccccccccc} 
& \multicolumn{4}{c}{ Neat liquid system } & \multicolumn{3}{c}{ Solution system (50\% n-dodecane) } \\
\cline { 2 - 9 } & \multicolumn{2}{c}{75 POP:25OPO } & 25 POP:75OPO & \multicolumn{2}{c}{75 POP:25OPO } & 25 POP:75OPO \\
\cline { 2 - 8 } & $\beta_{\mathrm{POP}}$ & $\beta_{\mathrm{MC}}$ & $\beta_{\mathrm{OPO}}$ & $\beta_{\mathrm{MC}}$ & $\beta_{\mathrm{POP}}$ & $\beta_{\mathrm{MC}}$ & $\beta_{\mathrm{OPO}}$ & $\beta_{\mathrm{MC}}$ \\
\hline \multirow{2}{*}{$\mathrm{T}_{\mathrm{m}}$} & 35 & 32 & 22 & 31 & 27 & 17 & 6 & 20 \\
\hline
\end{tabular}

(16) ${ }^{6}(25)$

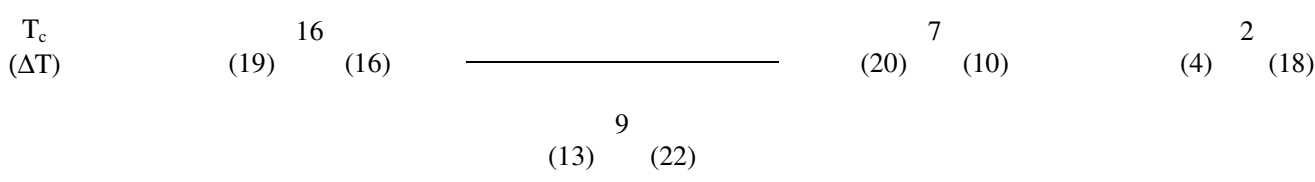

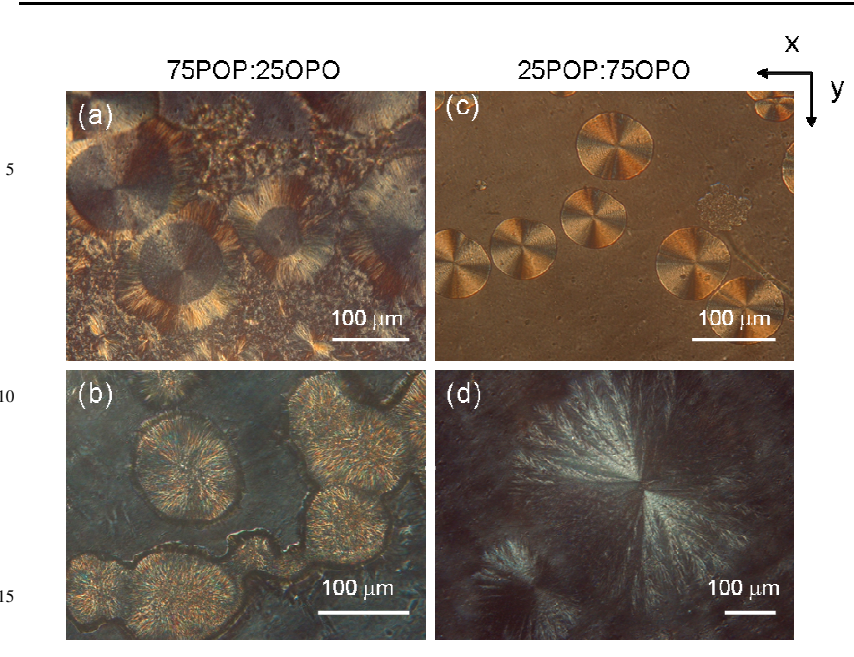

Fig.2 Polarized microscopic images of spherulites of POP:OPO binary mixtures. (a) $75 \mathrm{POP}: 25 \mathrm{OPO}$ (neat liquid) grown at $16^{\circ} \mathrm{C}$, (b)

20 75POP:25OPO (50\% n-dodecane) grown at $7{ }^{\circ} \mathrm{C}$, (c) 25POP:75OPO (neat liquid) grown at $6{ }^{\circ} \mathrm{C}$ and (d) 25POP:75OPO (50\% n-dodecane) grown at $2{ }^{\circ} \mathrm{C}$. $\mathrm{X}$ and $\mathrm{Y}$ directions in the spherulites are shown.

between two Mylar films to obtain thin layers in which crystallization occurred. The films were set on a temperature25 controlled Linkam stage and quickly cooled from $50^{\circ} \mathrm{C}$ to crystallization temperature $\left(\mathrm{T}_{c}\right)$, at which the $\mathrm{SR}-\mu-\mathrm{XRD}$ experiments were carried out. The values of $T_{c}$ are presented in Table 2. At least two different spherulites were measured in every case.

30 In order to confirm the polymorphic forms of TAGs, laboratory-scale X-ray diffraction (XRD) was also performed (RINT-TTR, Rigaku Co., Tokyo, Japan, $\lambda=0.154 \mathrm{~nm}$ ) using a rotator-anode $\mathrm{X}$-ray beam generator.

\section{${ }_{35}$ Results \\ Optical Characterization of Spherulites}

Figure 2 depicts polarized microscopic images of the spherulites of the mixtures of 75POP:25OPO and 25POP:75OPO grown from neat liquid and 50\% n-dodecane 40 solution. In Fig. 2(a) of 75POP:25OPO, large and many small spherulites coexisted when grown from neat liquid. The diameters of the large spherulites were $150 \mu \mathrm{m}$, and those of the small spherulites were less than $20 \mu \mathrm{m}$. We observe aggregation of small spherulites between the large spherulites.

45 One may reasonably expect that the large spherulites started growing later than the small spherulites. Although not shown here, we performed SR- $\mu$-XRD analysis on the aggregated small spherulites. In these spherulites, the polymorphic occurrence and lamellar direction were quite 50 random, and not every spherulite was distinguished from the others. Therefore, SR- $\mu$-XRD analysis was performed on only the large spherulites. It is evident that in every typical large spherulite of 75POP:25OPO depicted in Fig. 2(a), morphology in the central part differs from that in the peripheral part: a ${ }_{55}$ compact pattern is observed in the central area and needle patterns appear in the peripheral areas. In contrast, for 25POP:75OPO grown from neat liquid (Fig. 2(c)), every spherulite has a uniform pattern of polarized-crossing without any separated inner textures.

60 The spherulites grown from 50\% n-dodecane solution have uniform morphology in which needle patterns are arranged parallel to the radial direction from the central to the outer regions of the spherulites.

\section{SR- $\mu$-XRD Analysis}

${ }_{65}$ Spherulites grown from neat liquid 


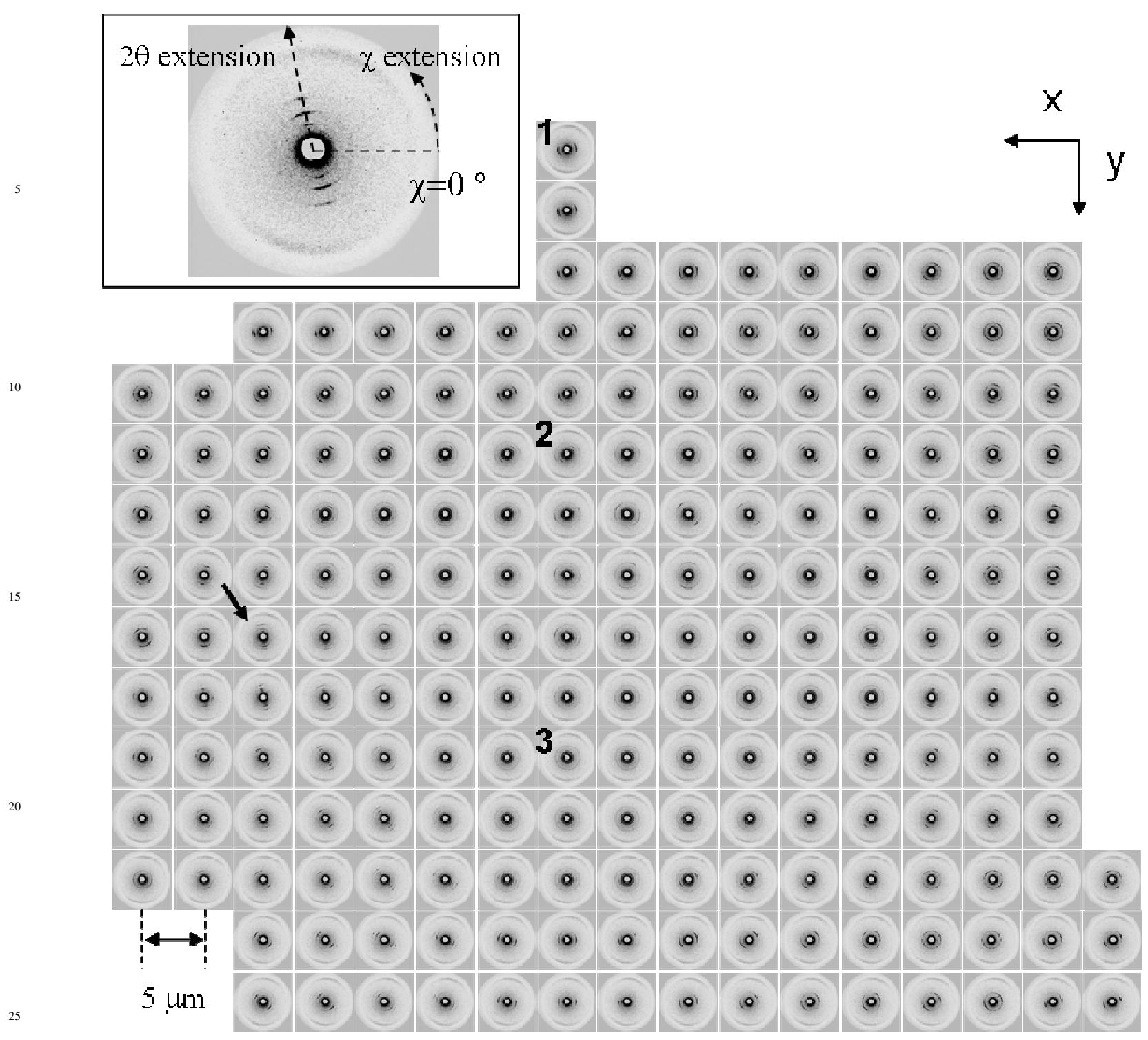

Fig. 3 Scanning SR- $\mu$-XRD patterns taken at the all positions of a spherulite of the mixture of 75POP:25OPO grown from neat liquid, and enlarged 2D pattern of the position noted by an arrow (inserted).

30 The samples were cooled from $50^{\circ} \mathrm{C}$ to $16^{\circ} \mathrm{C}$ for the 75POP:25OPO mixture, and $6^{\circ} \mathrm{C}$ or $9^{\circ} \mathrm{C}$ for the 25POP:75OPO mixture, where isothermal stabilization was applied to grow large spherulites before the SR- $\mu$-XRD experiments.

Figure 3 depicts scanning SR- $\mu$-XRD patterns taken at 204 35 individual positions in an $80 \mu \mathrm{m}$-diameter spherulite of the 75POP:25OPO mixture. Microbeam scanning was performed at a distance of $5 \mu \mathrm{m}$, and all the patterns indicated clear diffraction peaks from the crystals in the areas where the microbeam was irradiated.

40 As a typical example, an enlarged 2D diffraction pattern at a position is denoted by the arrow in the inset box in Fig. 3, where the diffraction angle $(2 \theta)$ and the azymuthal angle $(\chi)$ extensions are indicated. The detailed analysis of $2 \theta$ and $\chi$ extensions is reported elsewhere. ${ }^{20}$ The pair of white and 45 black patterns at the central position corresponds to the beam stopper and direct beam, and the broad grey circle at the periphery position corresponds to Mylar film. Two sets of 


\section{Cite this: DOI: $10.1039 / \mathrm{c0xx} 00000 \mathrm{x}$}

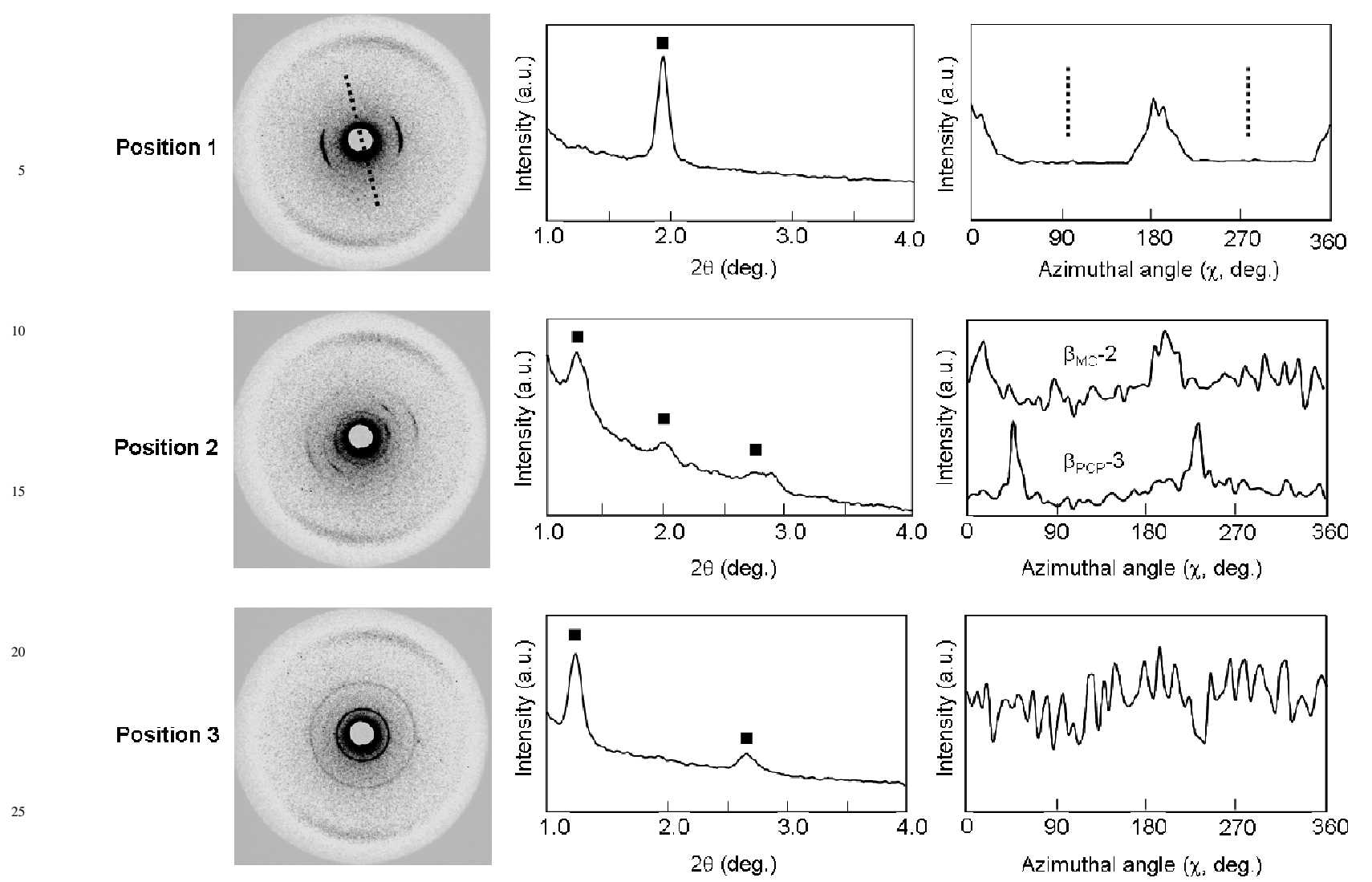

Fig. 4 Enlarged patterns taken at three positions noted by 1, 2 and 3 in Fig. 3. 2D diffractions patterns (left), $2 \theta$ extension (middle) and $\chi$ extension (right).

30 three sharp arc peaks are identified, indicating the presence of two different types of crystals having well-ordered lamellar orientations. These sharp peaks were analyzed in two ways: the $2 \theta$ extension provides information on the long spacing of crystals, and the $\chi$ extension indicates the lamellar direction 35 of the crystals.

To precisely analyze the spatial distribution of MCPOP:OPO and POP crystals within the spherulite, Fig. 4 depicts enlarged 2D patterns and corresponding $2 \theta$ and $\chi$ extension patterns taken at three positions along the radial direction from the 40 central to outer regions of the spherulite (denoted as positions 1, 2, and 3 in Fig. 3).

The $2 \theta$ extension pattern of position 1 indicates a single peak (denoted by $\square$ ) at $2 \theta=2.0^{\circ}$, which corresponds to the 002 reflection of the $6.4 \mathrm{~nm}$ long spacing. This value ${ }_{45}$ corresponds to the long spacing of $\beta_{\mathrm{POP}}-3 .{ }^{13}$ The $\chi$ extension has two sharp peaks at $\chi=5^{\circ}$ and $185^{\circ}$, although each peak is split into two. No peak is observed at any $\chi$ value except for these two peaks; therefore, we conclude that the lamellar planes of the crystals at this position are aligned along the ${ }_{50}$ direction denoted by broken lines in the figure. In this way, we can interpret the $2 \mathrm{D}$ diffraction patterns of the other two positions.

Position 2 indicates two sets of arc peaks, providing three peaks in the $2 \theta$ extension (denoted by $\mathbf{m}$ ). The peaks at ${ }_{55} 2 \theta=1.3^{\circ}$ and $2.7^{\circ}$ correspond to the 001 and 002 reflections of the $4.6 \mathrm{~nm}$ long spacing, which corresponds to $\beta_{\mathrm{MC}}-2$. The peak at $2 \theta=2.0^{\circ}$ corresponds to the 002 reflection of the $6.4 \mathrm{~nm}$ long spacing of $\beta$ POP- 3 . From these results, we can conclude that two kinds of crystals $\left(\beta_{\mathrm{MC}}-2\right.$ and $\left.\beta_{\mathrm{POP}}-3\right)$ exist at 60 this position. Interesting results are indicated for the $\chi$ extension, since the arrangements of lamellar planes of the $\beta_{\mathrm{MC}-2}$ and $\beta_{\mathrm{POP}-}-3$ crystals differ. In the $\chi$ extension patterns of the $\beta_{\mathrm{MC}}-2$ crystals, broad peaks appear at maximum $\chi$ values of $15^{\circ}$ and $195^{\circ}$; however, sharp peaks appear at $45^{\circ}$ 65 and $225^{\circ}$ for the $\beta_{\mathrm{POP}}-3$ crystals. This result indicates that the lamellar directions of the $\beta_{\mathrm{MC}}-2$ and $\beta_{\mathrm{POP}}-3$ crystals differ by $30^{\circ}$ at this position.

Finally, at position 3, which is near the central part of the spherulite, only $\beta_{\mathrm{MC}}-2$ crystals exist and have a randomly 70 oriented lamellar arrangement. This conclusion could be drawn by observing that the peaks at $2 \theta=1.3^{\circ}$ and $2.7^{\circ}$ correspond to the $4.6 \mathrm{~nm}$ long spacing and that the diffraction peaks have almost the same intensity at all 


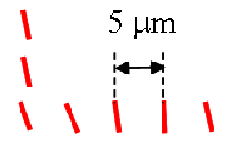

\section{$11111+11 / 1 /$}

$1111111111 / 1 / 2 \times x$

$\times \times \times \times 11111 * 1 / 1 \times 1,10$

$\times x \times x \times 1>111111, x>$

$x \times \times x \times>1>-* * * *->$

一ー 一ー -

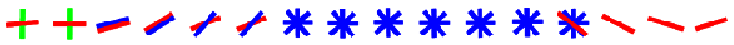

| / / / /

$1 / 1 / 1$ *

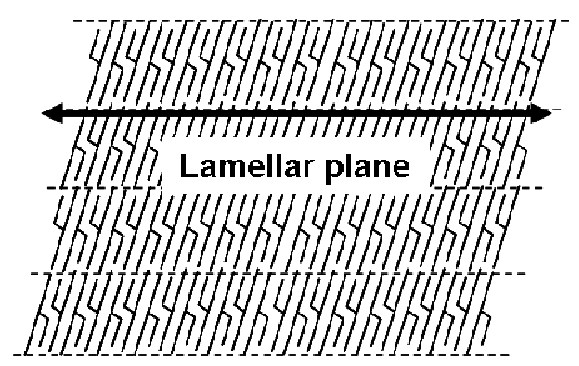

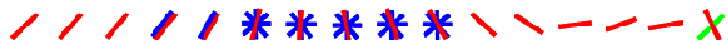

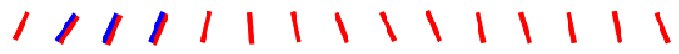

$1 / 1111111111111$

Fig. 5 Lamellar plane directions of the crystals at the all positions examined of the spherulite of 75POP:25OPO shown in Fig.3. Red and blue lines correspond to $\beta_{\mathrm{POP}}-3$ and $\beta_{\mathrm{MC}}-2$, respectively. Green lines correspond to the crystals of neighboring spherulites. Star-like pattern means random orientation of the lamellar plane.

1111118

11111111110

$1+11111111 \%$

$\rightarrow+1+1111111 \%$

$\rightarrow+1+11111<-<$ $-1+1+1+1111 / 1,1<1$

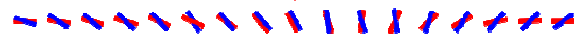

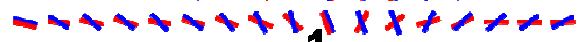

(a)

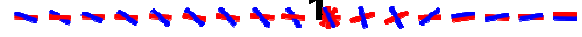

$-\infty \times \times \times \times \times \times \times \times \times<\times<\times$

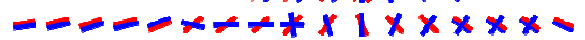

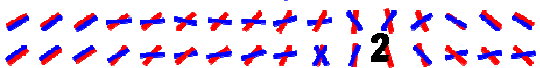

$1<<+<1<+\mid 111+$

$\leftrightarrow-\infty+1|1| 1 \mid 11$

10 $\mathrm{um}$
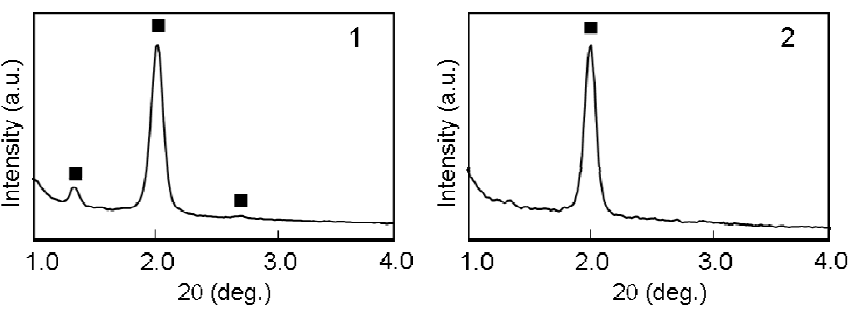

\section{$1,1,1,1$}

$11111111 / 1$

$1,11111,1111$

$\rightarrow \infty 111111,1$

$\rightarrow-\infty>1211,1,-\infty$

$\rightarrow \rightarrow-\infty 111,1<-\infty$

$----\cdots+1,-\infty$

(b)
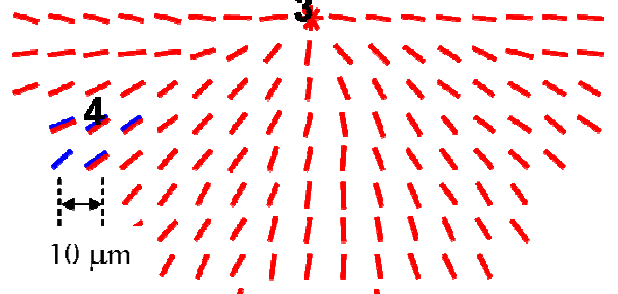
1 I
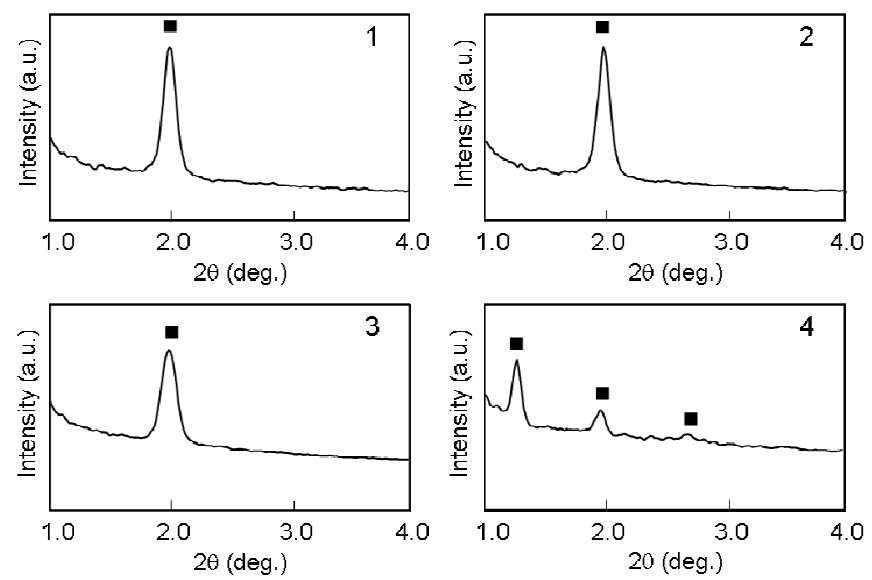

Fig. 6 SR- $\mu$-XRD data of spherulites of 25POP:75OPO mixtures grown from neat liquid (a) at $9{ }^{\circ} \mathrm{C}$ and (b) at $6{ }^{\circ} \mathrm{C}$. Left; lamellar plane directions, right: $2 \theta$ extension patterns. Blue and red lines correspond to $\beta_{\mathrm{MC}}-2$ and $\beta_{\mathrm{OPO}}-3$, respectively. 
(a)

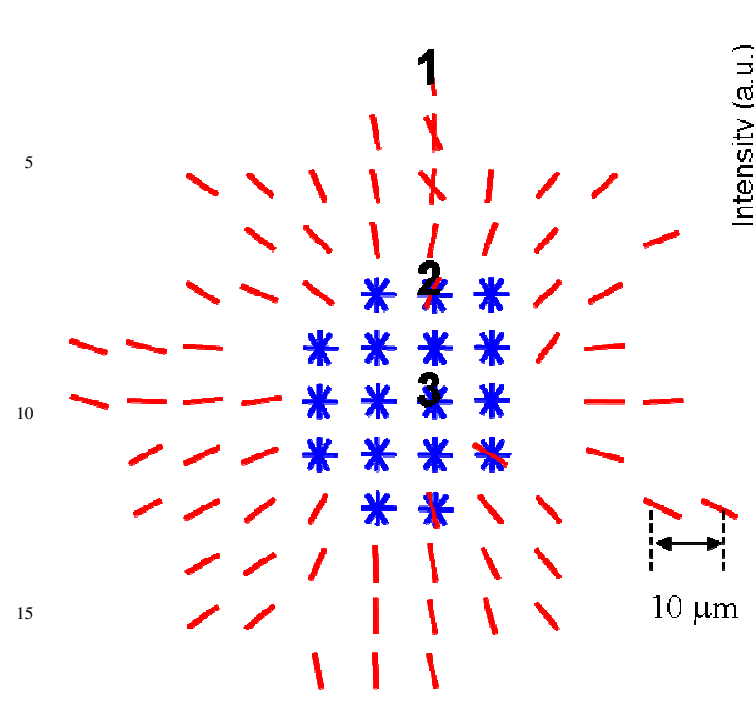

(b)
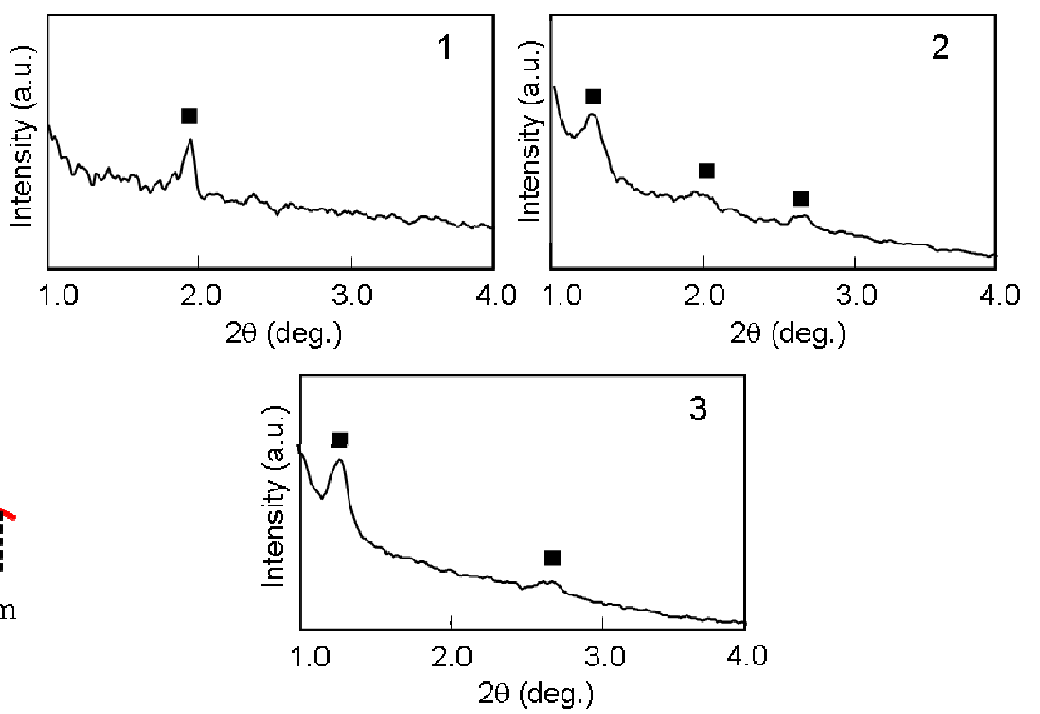

Fig. 7 SR- $\mu$-XRD data of spherulites of 75POP:25OPO mixture grown from n-dodecane solution at $7^{\circ} \mathrm{C}$. (a ) Lamellar plane directions and (b) $2 \theta$ 20 extension patterns taken at the positions noted in (a). Blue and red lines correspond to $\beta_{\mathrm{MC}}-2$ and $\beta_{\mathrm{OPO}}-3$, respectively.

the azymuthal angles, although the patterns were highly noisy. From the results presented in Fig. 4, it was evident that the predominant TAG crystals varied from $\beta_{\mathrm{MC}}-2$ to $\beta_{\mathrm{POP}-3}$ when 25 the microbeam scanning positions changed from the central regions to the outer regions in the same spherulite.

Figure 5(a) illustrates the spatial distribution of $\beta_{\mathrm{POP}}-3$ and $\beta_{\mathrm{MC}-2}$ crystals in the spherulite depicted in Fig. 3 and indicates their lamellar directions (Fig. 5(b)). The $\beta_{\mathrm{MC}-2}$ 30 crystals with random lamellar orientation occupy the central part of the spherulite (area of $30 \times 40 \mu \mathrm{m}^{2}$ ). However, predominant crystals vary from $\beta_{\mathrm{MC}-2}$ to $\beta_{\mathrm{POP}-3}$ when the position moves from the central to the peripheral areas of the spherulite, as explained above. In addition, the lamellar plane 35 directions of the $\beta_{\mathrm{POP}}-3$ crystals are arranged parallel to the radial direction of the spherulite. Between the periphery and the central areas of the spherulite are some areas where $\beta_{\mathrm{MC}-2}$ and $\beta_{\text {POP- }} 3$ crystals co-exist. The lamellar directions of the $\beta_{\mathrm{MC}}-2$ and $\beta_{\mathrm{POP}-3}$ crystals are almost parallel, with some 40 exceptions (e. g., position 2 in Fig. 4).

Figure 5(a) also depicts many crystals whose lamellar planes make right angles at the periphery areas of the spherulite (green lines). These areas overlap with the neighbouring spherulites (see Fig. 2(a)). Interestingly, the 45 crystals of the neighboring spherulites are all $\beta_{\mathrm{POP}}-3$. This result indicates that perhaps the heterogeneous structure of the spherulite examined in Figs. 3 through 5 also exists in the neighboring spherulites that have $\beta_{\mathrm{POP}} 3$ crystal in their peripheral zones.

50 Figure 6 presents the results of SR- $\mu$-XRD experiments of the spherulites of the 25POP:75OPO mixture grown from neat liquid at $9^{\circ} \mathrm{C}$ and $6^{\circ} \mathrm{C}$. Two spherulites were analyzed, following the same methodology than in the case before, over the whole area by scanning SR- $\mu$-XRD studies at each 55 temperature, and the same results were obtained. It must be noted that microbeam X-ray scanning was performed at $10 \mu \mathrm{m}$ distance in both cases.

For spherulites grown at $9^{\circ} \mathrm{C}$ (Fig. 6(a)), concurrent crystallization of $\beta_{\mathrm{MC}}-2$ and $\beta_{\mathrm{OPO}}-3$ was observed at almost ${ }_{60}$ every position. However, the concentration of $\beta_{\text {OPO }}-3$ crystals was always higher than that of $\beta_{\mathrm{MC}-2}$ at the positions where the two crystals co-existed. Furthermore, only $\beta_{\text {OPo- }} 3$ crystals were observed at some places. Two typical examples are the $2 \theta$ extension patterns at positions 1 and 2 in Fig. 6(a). There 65 are three peaks at position 1 (denoted by $\mathbf{m}$ ). The peaks at $2 \theta=1.3^{\circ}$ and $2.7^{\circ}$ correspond to the 001 and 002 reflections of the $4.6 \mathrm{~nm}$ long spacing of $\beta_{\mathrm{MC}-2}$, whereas the peak at $2 \theta=2.0^{\circ}$ corresponds to the 002 reflection of the $6.4 \mathrm{~nm}$ long spacing of $\beta_{\mathrm{OPO}}-3$. The relative concentration ratio of the ${ }_{70} \beta_{\mathrm{OPO}}-3$ and $\beta_{\mathrm{MC}}-2$ crystals should be compared by considering the peak intensity of the 002 reflections. It is clear that the peak intensity of $\beta_{\mathrm{OPO}-}-3$ is much higher than that of $\beta_{\mathrm{MC}}-2$. As an extreme case, position 2 has only one peak of $\beta_{\text {opo- }}$. Thus, the predominant crystallization of $\beta_{\mathrm{OPO}}-3$ over $\beta_{\mathrm{MC}}-2$ 75 was confirmed at 231 of the 241 positions in Fig. 6(a). At the 
(a)

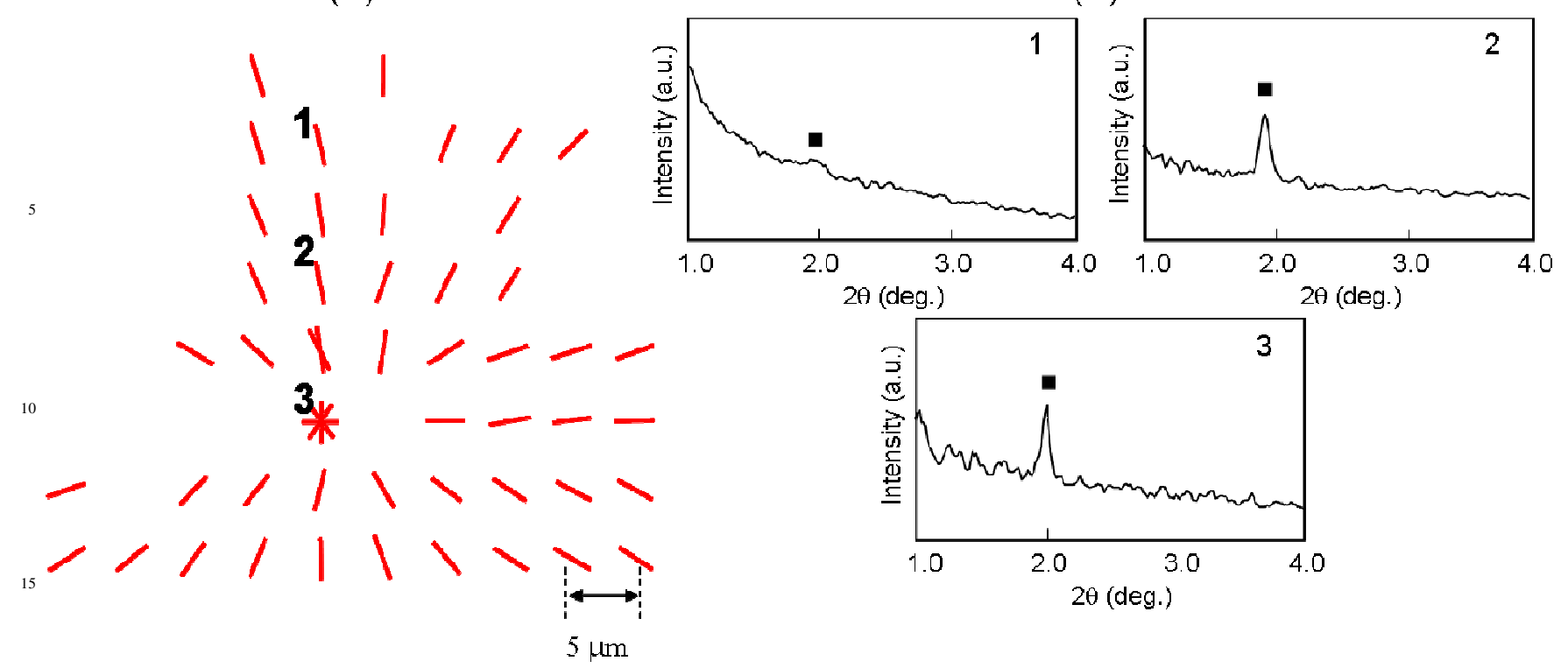

Fig. 8 SR- $\mu$-XRD data of spherulites of 25POP:75OPO mixture grown from n-dodecane solution at $2{ }^{\circ} \mathrm{C}$. (a ) Lamellar plane directions and (b) $2 \theta$ extension patterns taken at the positions noted in (a).

other positions, either $\beta_{\mathrm{OPO}-}-3$ and $\beta_{\mathrm{MC}}-2$ or only $\beta_{\mathrm{MC}}-2$ was predominant, but this feature was not common to all the positions of this spherulite. The predominant crystallization of ${ }_{25} \beta_{\text {OPO- }} 3$ thus covered $95 \%$ of the area in this spherulite.

The lamellar directions of the $\beta_{\mathrm{OPO}-3}$ and $\beta_{\mathrm{MC}}-2$ crystals in Fig. 6(a) were parallel to the radial direction of the spherulite at the outer regions. However, the lamellar directions were more or less random in the central region.

30 Figure 6(b) depicts the SR- $\mu$-XRD patterns taken at 225 positions of the spherulite of the 25POP:75OPO mixture grown at $6^{\circ} \mathrm{C}$. In this case, only $\beta$ оро- 3 was observed at 217 positions, concurrent crystallization of $\beta_{\mathrm{OPO}}-3$ and $\beta_{\mathrm{MC}}-2$ was observed at six positions, and $\beta_{\mathrm{MC}-2}$ appeared without $\beta_{\mathrm{OPO}}-3$ 35 at two positions. The lamellar directions of all the crystals were parallel to the radial direction of the spherulite in almost all the regions, except the central position.

From analysis of the spherulites of the 25POP:75OPO mixture grown at two temperatures (Fig. 6), we conclude that 40 the rate of crystallization of $\beta_{\mathrm{OPO}-}-3$ crystals was higher than that of $\beta_{\mathrm{MC}}-2$ crystals in the range of growth temperatures examined.

\section{Spherulites grown from n-dodecane solution} 45

When n-dodecane was added to the binary mixtures of POP and OPO, SR- $\mu$-XRD intensity decreased compared to that of the neat liquid system. Nevertheless, the behavior of the samples and the results obtained were the same as for those
50 grown from neat liquid for the mixtures of both 75POP:25OPO and 25POP:75OPO.

Figure 7(a) illustrates the lamellar plane directions of the crystals at 79 positions indicating clear SR- $\mu$-XRD patterns for the 167 positions examined at $10 \mu \mathrm{m}$ distance in the 55 spherulite of the 75POP:25OPO mixture grown at $7^{\circ} \mathrm{C}$ in $50 \%$ solution. Having performed the same analyses as for Figs. 3 through 6 , we can draw the following conclusions about the heterogeneous microstructure of the spherulite depicted in Fig. 7. The central part of the spherulite is occupied by $\beta_{\mathrm{MC}-2}$ 60 and $\beta_{\text {POP }}-3$ concurrently crystallized in the intermediate area, and $\beta_{\mathrm{POP}}-3$ is predominant in the outer zone. The lamellar plane directions of $\beta_{\mathrm{MC}}-2$ crystals in the central region are random, whereas a well-ordered lamellar arrangement parallel to the radial direction is observed in the periphery regions ${ }_{65}$ where $\beta_{\mathrm{POP}-3}$ crystals predominate. These properties are basically the same as those of the spherulites of the 75POP:25OPO mixture grown from neat liquid in Figs. 3 through 5.

Finally, SR- $\mu$-XRD patterns were taken at 107 positions of 70 the spherulite of the 25POP:75OPO mixture grown at $2{ }^{\circ} \mathrm{C}$, and the lamellar plane directions at 48 positions are presented in Fig. $8(\mathrm{a})$, with $5 \mu \mathrm{m}$ between consecutive positions. The results were the same as those observed in 25POP:75OPO mixture grown from neat liquid: $\beta_{\mathrm{OPO}}-3$ predominated over $75 \beta_{\text {MC }} 2$. Namely, $\beta_{\text {opo- }} 3$ was always observed, and no $\beta_{\mathrm{MC}-2}$ crystals appeared. The lamellar plane directions of the $\beta$ оро- 3 
Table 3 Long spacing values of $\beta_{\mathrm{POP}}, \beta_{\mathrm{OPO}}$ and $\beta_{\mathrm{MC}}$ crystals obtained with synchrotron radiation microbeam X-ray- diffraction (SR- $\mu$-XRD) and synchrotron radiation macrobeam X-ray- diffraction (SR-XRD)

\begin{tabular}{|c|c|c|c|c|c|c|c|c|c|}
\hline \multirow{3}{*}{$\begin{array}{l}\text { Long spacing }(\mathrm{nm}) \\
\text { Chain Length Structure }\end{array}$} & \multicolumn{3}{|c|}{$S R-\mu-X R D$} & \multicolumn{3}{|c|}{$\begin{array}{c}\text { SR-XRD } \\
\text { (neat liquid) }^{13}\end{array}$} & \multicolumn{3}{|c|}{$\begin{array}{c}\text { SR-XRD } \\
(50 \% \text { n-dodecane solution })^{14}\end{array}$} \\
\hline & $\begin{array}{c}\beta_{\mathrm{POP}} \\
6.4\end{array}$ & $\begin{array}{c}\beta_{\mathrm{OPO}} \\
6.4\end{array}$ & $\begin{array}{l}\beta_{\mathrm{MC}} \\
4.6\end{array}$ & $\begin{array}{c}\beta_{\mathrm{POP}} \\
6.4\end{array}$ & $\beta_{\mathrm{OPO}}$ & $\beta_{\mathrm{MC}}$ & $\beta_{\mathrm{POP}}$ & $\beta_{\mathrm{OPO}}$ & $\beta_{\mathrm{MC}}$ \\
\hline & $\begin{array}{l}0.4 \\
\text { Triple }\end{array}$ & $\begin{array}{l}0.4 \\
\text { Triple }\end{array}$ & $\begin{array}{c}4.0 \\
\text { Double }\end{array}$ & $\begin{array}{l}0.4 \\
\text { Triple }\end{array}$ & $\begin{array}{c}0.4 \\
\text { Triple }\end{array}$ & $\begin{array}{c}4.2 \\
\text { Double }\end{array}$ & $\begin{array}{c}0.1 \\
\text { Triple }\end{array}$ & $\begin{array}{c}6.4 \\
\text { Triple }\end{array}$ & $\begin{array}{c}4.3 \\
\text { Double }\end{array}$ \\
\hline
\end{tabular}

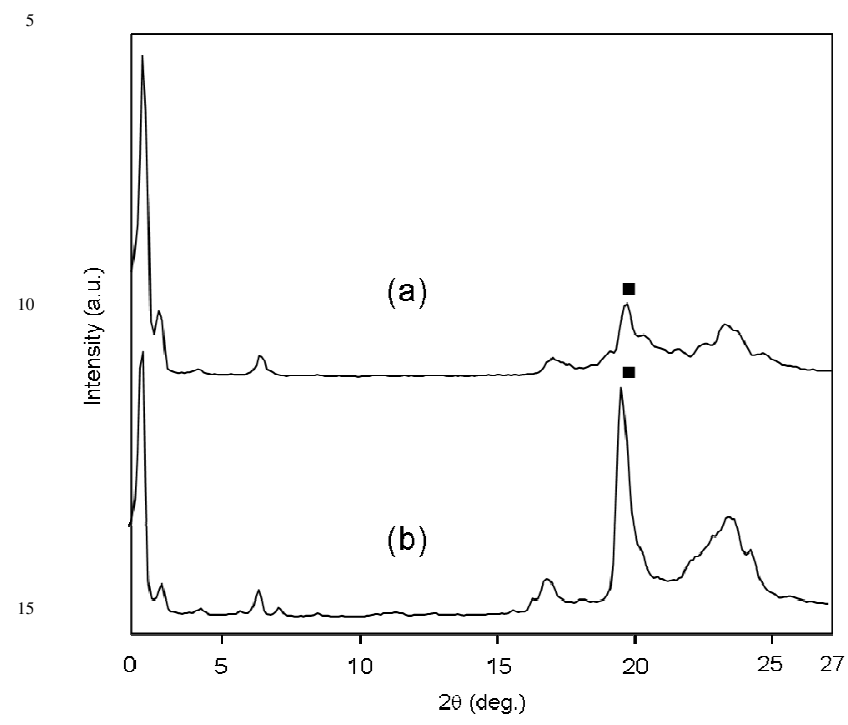

Fig. 9 SAXD and WAXD patterns of the mixtures of (a) 75POP:25OPO mixture and (b) 25POP:75OPO mixture grown from neat liquid.

20 crystals were parallel to the radial direction of the spherulites in all the regions except the central position.

\section{SAXD and WAXD Patterns}

We have presented the SR- $\mu$-XRD results of the spherulites of 25 75POP:25OPO and 25POP:75OPO mixtures grown from neat liquid and n-dodecane solutions, and we examined them with small-angle X-ray diffraction (SAXD). The long spacing values of the POP, OPO, and MCPOP:OPO crystals examined in the present SR- $\mu$-XRD study are summarized in Table 3, 30 compared with those reported in previous analysis with conventional synchrotron radiation X-ray diffraction (SR$\mathrm{XRD}$ ). The chain-length structures of the POP, OPO, and MCPOP:OPO crystals are all the same in the three studies: $\mathrm{MC}_{\mathrm{POP}: O P O}$ crystals have a double-chain-length structure, and 35 the other two components have triple-chain-length structures. Although the precise long spacing values differ slightly (by $0.1 \sim 0.3 \mathrm{~nm}$ ) among the studies with SR- $\mu$-XRD and SR-XRD, this uncertainty is within experimental error. However, in order to confirm the polymorphic forms of TAG crystals, we
40 observed the wide-angle X-ray diffraction (WAXD) peaks using RINT because WAXD patterns are more sensitive to subcell structures, such as tricilinic parallel $\left(\mathrm{T}_{/ /}\right)$for $\beta$ polymorph or orthorhombic perpendicular $\left(\mathrm{O}_{\perp}\right)$ for $\beta$, polymorph.

45 For this purpose, we performed laboratory-scale XRD using a RINT apparatus (laboratory scale X-ray diffraction). Figure 9 depicts the WAXD and SAXD patterns of the crystals of 75POP:25OPO mixtures grown from neat liquid at $16^{\circ} \mathrm{C}$ and for 25POP:75OPO mixtures grown from neat liquid at $6^{\circ} \mathrm{C}$.

${ }_{50}$ The SAXD patterns of the two mixtures are the same as those observed with SR- $\mu$-XRD. The WAXD patterns were typical of $\beta$ polymorph, since a strong peak of $0.46 \mathrm{~nm}$ at $2 \theta=19^{\circ}$ was observed in the two mixtures (denoted by $\square$ ). Having confirmed the presence of $\beta$ forms for POP, OPO, and ${ }_{55} \mathrm{MC}$ POP:OPO in the 75POP:25OPO and 25POP:75OPO mixture samples with the RINT XRD, we performed the SR- $\mu$-XRD experiments.

As with XRD studies of crystals grown from n-dodecane solutions containing $50 \%$ of fat samples, it was quite difficult 60 to obtain clear diffraction patterns with RINT because the diffraction peaks from the solution samples were too weak. However, the mixing behavior of POP:OPO in n-dodecane solution examined with SR-XRD demonstrated that the equilibrium states contained $\beta$ forms of POP, OPO, and ${ }_{65} \mathrm{MC}$ POP:OPO. ${ }^{14}$ As equilibration from metastable to most stable forms occurs much faster in the solution system than in neat liquid systems, we conclude that the spherulites of the mixtures of POP:OPO grown from n-dodecane solution are all $\beta$ forms.

\section{${ }_{70}$ Discussion}

In the present study, we observed the microstuctures of spherulites of 75POP:25OPO and 25POP:75OPO with SR- $\mu$ XRD. Mixtures having these two ratios were chosen because previous studies indicated that the averaged concentration 75 ratios of POP:MCPOP:OPO and OPO:MCPOP:OPO are 50:50 in the mixtures of 75POP:25OPO and 25POP:75OPO, due to the fact that POP and OPO form MCPOP:OPO crystals at the ratio of 50:50. Therefore, we expected that the microstructures of spherulites might not be homogeneous, due to differences in 80 the rates of crystallization of POP, МСPOP:OPO, and OPO, and 
Table 4 Occurrence frequency of $\beta_{\mathrm{OPO}}$ and $\beta_{\mathrm{MC}}$ in 25POP:75OPO mixture grown from neat liquid examined by scanning SR- $\mu$-XRD at different positions over many small spherulites at two crystallization temperatures $\left(\mathrm{T}_{\mathrm{c}} \mathrm{s}\right)$ (a)

10

15

\begin{tabular}{|c|c|c|}
\hline & $\begin{array}{c}\mathrm{T}_{\mathrm{c}}=6{ }^{\circ} \mathrm{C} \\
(45 \text { positions })\end{array}$ & $\begin{array}{c}\mathrm{T}_{\mathrm{c}}=9^{\circ} \mathrm{C} \\
(83 \text { positions })\end{array}$ \\
\hline$\beta_{\mathrm{OPO}}>\beta_{\mathrm{MC}}$ & 43 & 83 \\
\hline$\beta_{\mathrm{OPO}} \sim \beta_{\mathrm{MC}}$ & 1 & 0 \\
\hline$\beta_{\mathrm{OPO}}<\beta_{\mathrm{MC}}$ & 1 & 0 \\
\hline
\end{tabular}

(b)

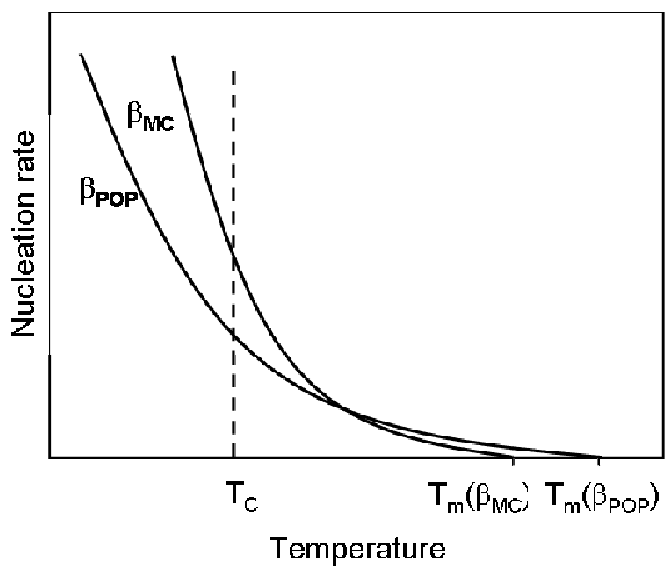

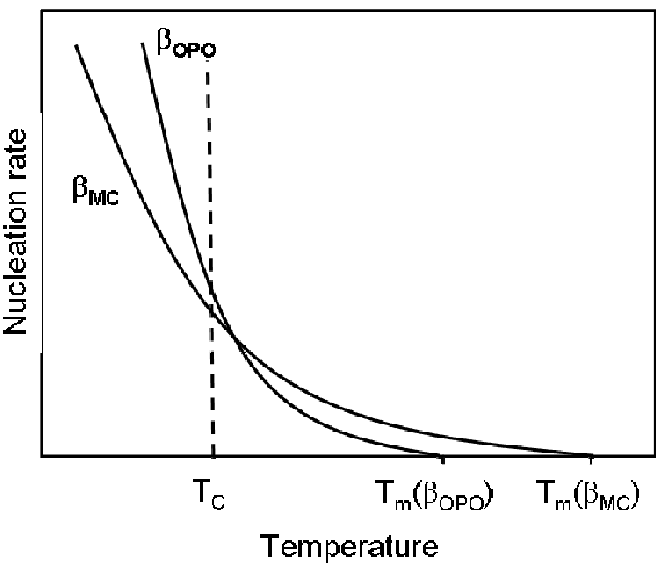

Fig. 10 Schematic figures of nucleation rate of $\beta_{\mathrm{POP}}, \beta_{\mathrm{MC}}$ and $\beta_{\mathrm{OPO}}$ as a function of temperature in the mixtures of (a) 75POP:25OPO and (b) 25POP:75OPO. $\mathrm{T}_{\mathrm{c}}$, crystallization temperature.

that such heterogeneous structures can be analyzed solely with SR- $\mu$-XRD experiments, as reported in our previous studies of spherulites of a simple TAG system, ${ }^{20}$ granular crystals in fat spreads, ${ }^{39}$ and oil-in-water emulsion droplets. ${ }^{37,38}$

25 The results obtained by the present experiments are summarized in the following.

(1) For mixtures of 75POP:25OPO, large spherulites grown from both neat liquid and n-dodecane solution were dominated by MCPOP:OPO in the inner regions, whereas the 30 outer region was dominated by POP. From this result, we conclude that the relative crystallization rate of $\mathrm{MC}_{\mathrm{POP}: \mathrm{OPO}}$ was higher than that of POP because we can reasonably assume that crystals having higher rates of nucleation may first occur in the central part of the spherulite, and successive 35 nucleation and crystal growth having lower rates of nucleation may occur afterward and extend to the outer part of the spherulite at the $\mathrm{T}_{\mathrm{c}}$ examined.

(2) For mixtures of 25POP:75OPO, the entire area was homogeneously occupied either with almost exclusively OPO 40 or with coexisting MCPOP:OPO and OPO (Table 4). This result indicates that the relative nucleation rate of OPO is higher than, or at least similar to, that of $\mathrm{MC}_{\mathrm{POP}: \mathrm{OPO}}$ at the $\mathrm{T}_{\mathrm{c}}$ examined.

Based on these results, we may determine relative rates of 45 crystallization of POP and MCРOP:OPO in the 75POP:25OPO mixture, and OPO and MCPOP:OPO in the 25POP:75OPO mixture, based on the following considerations.

(a) Spherulite formation starts from the inner regions and continues to the outer regions.

50 (b) As crystallization is performed during rapid cooling, no difference exists between crystallization temperatures at different positions of the spherulite, and the crystallization temperature is quickly reached. (c) Heterogeneity in the occurrence of different crystal 55 fractions is caused by relative rates of nucleation: the higher the nucleation rate, more dominated is the inner region of the spherulite.

As the nucleation rate of crystals largely increases with increased supercooling $(\Delta \mathrm{T}),{ }^{40}$ it is necessary to take into ${ }_{60}$ account the effects of $\Delta \mathrm{T}$ on crystal nucleation when we compare the relative nucleation rates of POP, OPO, and MCPOP:OPO. Table 2 presents the following $\Delta \mathrm{T}$ values: in the 75POP:25OPO mixtures, $19^{\circ} \mathrm{C}$ for POP and $16^{\circ} \mathrm{C}$ for $\mathrm{MC}_{\mathrm{POP}: \mathrm{OPO}}$ at $\mathrm{T}_{\mathrm{c}}=16^{\circ} \mathrm{C}$ from neat liquid, and $20^{\circ} \mathrm{C}$ for POP ${ }_{65}$ and $10^{\circ} \mathrm{C}$ for $\mathrm{MC}_{\mathrm{POP}: \mathrm{OPO}}$ at $\mathrm{T}_{\mathrm{c}}=7^{\circ} \mathrm{C}$ from $50 \%$ solution; in the mixtures of $25 \mathrm{POP}: 75 \mathrm{OPO}, 16^{\circ} \mathrm{C}$ for $\mathrm{OPO}$ and $25^{\circ} \mathrm{C}$ for $\mathrm{MC}_{\text {POP:OPO }}$ at $\mathrm{T}_{\mathrm{c}}=6^{\circ} \mathrm{C}, 13^{\circ} \mathrm{C}$ for $\mathrm{OPO}$ and $22^{\circ} \mathrm{C}$ for MCPOP:OPO at $\mathrm{T}_{\mathrm{c}}=9^{\circ} \mathrm{C}$ from neat liquid, and $4{ }^{\circ} \mathrm{C}$ for $\mathrm{OPO}$ and $18^{\circ} \mathrm{C}$ for $\mathrm{MC}_{\mathrm{POP}: \mathrm{OPO}}$ at $\mathrm{T}_{\mathrm{c}}=2^{\circ} \mathrm{C}$ from $50 \%$ solution. It is 70 evident that $\Delta \mathrm{T}$ is larger for the crystals having higher $\mathrm{T}_{\mathrm{m}}$ values at all $\mathrm{T}_{\mathrm{c}}$. However, differences in $\Delta \mathrm{T}$ between the crystals decrease when $T_{c}$ increases.

Taking into account the effects of $\Delta \mathrm{T}$ discussed above, we may reasonably assume the relative rates of nucleation of $\beta$ 75 forms of POP, OPO, and MCPOP:OPO at different $\mathrm{T}_{\mathrm{c}}$ as shown in Fig. 10.

Thus, the nucleation rate of $\beta_{\mathrm{MC}}$ may be higher than that of $\beta_{\text {POP }}$ at large $\Delta \mathrm{T}$ values in the mixtures of $75 \mathrm{POP}: 25 \mathrm{OPO}$ (Fig. 10(a)). In this case, $T_{c}$ may be below the temperature 80 where the nucleation rate of $\beta_{\mathrm{MC}}$ exceeds that of $\beta_{\text {POP. In }}$ contrast, the nucleation rate of $\beta_{\text {OPo may be slightly higher }}$ than, or similar to, that of $\beta_{M C}$ in the mixtures of 25POP:75OPO at the crystallization temperatures examined in the experiments (Fig. 10(b)). It is highly significant to observe 85 directly the relative nucleation rates of $\beta$ forms of POP, OPO, and MCРOP:OPO, by on-site observation, as has been performed 


\section{Cite this: DOI: $10.1039 / \mathrm{c0xx} 00000 x$}

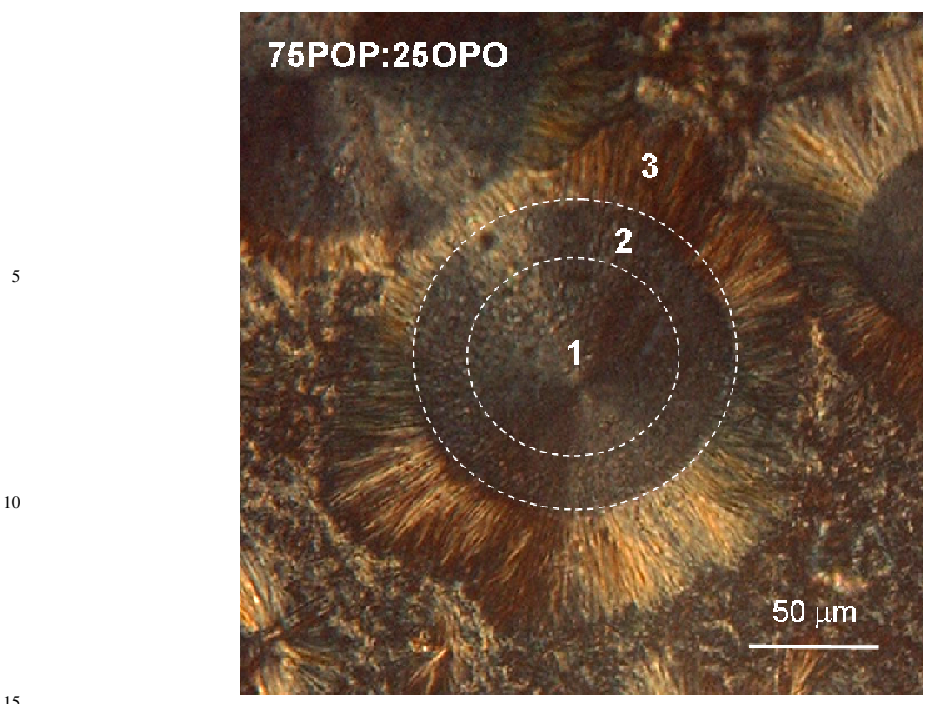

1. Central area: $\beta_{M C}$

2. Intermediate area: coexistence of $\beta_{\text {MC }}$ and $\beta_{\text {POP }}$

3. Periphery area: $\beta_{\mathrm{POP}}$
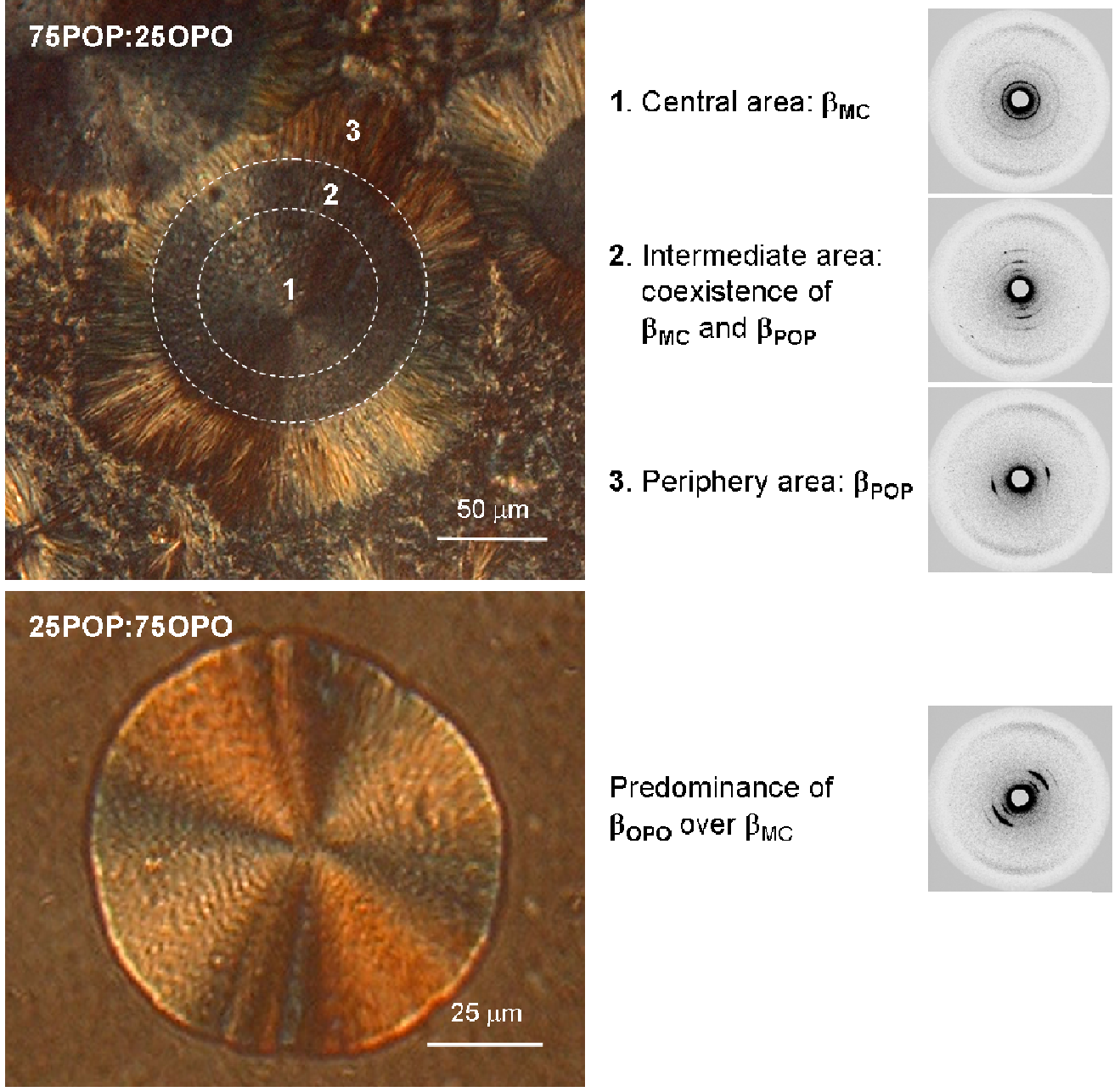

Predominance of $\beta_{\text {Opo over }} \beta_{M C}$

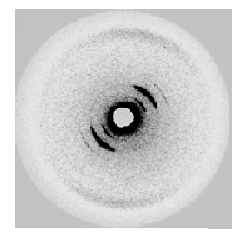

Fig. 11 Schematic figure showing the heterogeneous components distribution in the 75POP:25OPO and 25POP:75OPO mixtures.

on different polymorphic forms of OPO using a synchrotron radiation X-ray beam. ${ }^{41}$

\section{${ }_{30}$ Conclusion}

Microstructural studies of spherulites of the mixtures of $\mathrm{POP}+\mathrm{OPO}$ were examined at 75POP:25OPO and 25POP:75OPO in a neat liquid system and with 50\% ndodecane by using SR- $\mu$-XRD. This technique enabled the 35 scanning of samples in two dimensions to determine the exact composition at each point, with a difference in distance of $5 \mu \mathrm{m}$ or $10 \mu \mathrm{m}$. The results indicated that at $75 \mathrm{POP}: 25 \mathrm{OPO}$ a $\beta_{\mathrm{MC}}$ is located in the inner part of the spherulite and $\beta_{\mathrm{POP}}$ appears near the outer part. In contrast, for 25POP:75OPO, ${ }_{40} \beta$ OPO predominates over $\beta_{\mathrm{MC}}$ at the crystallization temperatures examined. This heterogeneous distributions were due to the different crystallization rates of MCPOP:OPO and component POP and OPO crystals, which were also confirmed by polarized microscopy: the morphology of spherulites of 45 75POP:25OPO grown from 50\% n-dodecane and 25POP:75OPO grown from neat liquid and 50\% n-dodecane were homogeneous, whereas those of 75POP:25OPO grown from neat liquid were heterogeneous (see Fig. 11). Although further study of the relative nucleation rates of these 50 polymorphic forms is required, knowing the compound distribution in the spherulitic system aids in the comprehension and prediction of growth mechanisms.

\section{Acknowledgments}

The authors acknowledge Dr. Gianfranco Mazzanti 55 (Dalhousie University, Canada) for valuable discussion.

They also acknowledge the financial support of the Ministerio de Ciencia y Tecnología through the CICYT (Project MAT2008-00497/NAN), the Generalitat de Catalunya 
through the Grup Consolidat (SGR 2009 1307), and the Ministerio de Educación through la Factoría Cristalográfica (Consolider-Ingenio, CSD2006-15) and through a Beca del Programa de Formación del Profesorado Universitario (FPU).

5 The experiments were performed with the approval of the Photon Factory Program Advisory Committee (Proposal Nos. 2010G114 and 2010G115). The authors gratefully acknowledge the help of Prof. A. Iida, Station Manager of Beamline 4A at Photon Factory (KEK Institute, Tsukuba, 10 Japan). The authors also appreciate experiment support provided by Dr. Y. Shinohara and Prof. Y. Amemiya (University of Tokyo).

\section{Notes and references}

15 a. Departament de Cristal-lografia, Mineralogia i Dipòsits Minerals, Facultat de Geologia, Universitat de Barcelona, Martí i Franquès s/n, E08028 Barcelona, Spain. FAX: (+34) 934021340; TEL: (+34) 934021350; E-mail: laurabayes@ub.edu

b. Graduate School of Biosphere Science, Hiroshima University, Higashi20 Hiroshima 739, Japan.

$\dagger$ Electronic Supplementary Information (ESI) available: Supplementary Text describing the details of the experimental set-up for carrying out the SR- $\mu$-XRD experiments. Figures showing the scanning SR- $\mu-X R D$ patterns taken at the all positions of the spherulites of the mixtures of: 25 25POP:75OPO grown from neat liquid (Figure S1), 75POP:25OPO grown from n-dodecane solution (Figure S2), 25POP:75OPO grown from $\mathrm{n}$-dodecane solution (Figure S3), and horizontal scanning SR- $\mu$-XRD patterns at different positions over many small spherulites of 25POP:75OPO mixture grown from neat liquid (Figure S4). See 30 DOI: $10.1039 / \mathrm{b} 000000 \mathrm{x} /$

1 K. Larsson, P. Quinn, K. Sato and F. Tiberg, eds. Lipids: Structure, Physical Properties and Functionality, The Oily Press, Bridgwater, England, 2006.

352 K. Sato and S. Ueno, in Bailey's Industrial Oil \& Fat Products, ed. F. Shahidi, John Wiley \& Sons, Inc., Hoboken, New Jersey, 2005, 1, pp 77-120.

3 A. I. Kitaigorodsky, Mixed Crystals, Springer Series in Solid-State Sciences, 33, Springer-Verlag Berlin Heidelberg, Germany, 1984.

404 K. Sato and S. Ueno, in Crystallization Processes in Fats and Lipid Systems,

ed. N. Garti and K. Sato, Marcel Dekker, New York, United States, 2001, pp.177-209.

5 C. C. Kulkarni, W. Wachter, G. Iglesias-Salto, S. Engelskirchen and

45 S. Ahualli, Phys. Chem. Chem. Phys., 2011, 13, 3004.

6 C. V. Kulkarni, T-Y. Tang, A. Seddon, J. M. Seddon, O. Ces and R. Templer, Soft Matter, 2010, 6, 3191.

7 J. M. Seddon, R. H. Templer, N. A. Warrender, Z. Huang, G. Cevc and D. Marsh, BBA-Biomembranes, 1997, 1327, 131.

508 R. H. Templer, J. M. Seddon, N. A. Warrender, A. Syrykh, Z. Huang, R. Winter and J. Erbes, J. Phys. Chem. B., 1998, 102, 7251.

9 A. Minato, S. Ueno, J. Yano, Z. H. Wang, H. Seto, Y. Amemiya and K. Sato, JAOCS., 1996, 73 (11), 1567.

10 D. M. Small, The Physical Chemistry of Lipids, Plenum, New York, United States, 1986, pp 345-394.

11 L. Zhang, S. Ueno, S. Miura and K. Sato, JAOCS., 2007, 84, 219.

12 A. Minato, S. Ueno, K. Smith, Y. Amemiya and K. Sato, J. Phys. Chem. B., 1997, 101 (18), 3498.

13 A. Minato, S. Ueno, J. Yano, K. Smith, H. Seto, Y. Amemiya and K. Sato, JAOCS., 1997, 74 (10), 1213.

14 E. Ikeda, S. Ueno, R. Miyamoto and K. Sato, J. Phys. Chem. B., 2010, 114 (34), 10961.

15 R. E. Timms, Eur. J. Lipid Sci. Technol., 2005, 107, 48.

16 A. G. Marangoni, Fat Crystal Networks, Marcel Dekker, New York, 652004.
17 N. C. Acevedo and A. G. Marangoni, Cryst. Growth Des., 2010, 10 (8), 3327.

18 N. C. Acevedo and A. G. Marangoni, Cryst. Growth Des., 2010, 10 (8), 3334

7019 Y. Nozue, R. Kurita, S. Hirano, N. Kawasaki, S. Ueno, A. Iida, T. Nishi and Y. Amemiya, Polymer, 2003, 44, 6397.

20 S. Ueno, T. Nishida and K. Sato, Cryst. Growth Des., 2008, 8 (3), 751.

21 K. Sato, T. Arishima, Z. H. Wang, K. Ojima, N. Sagi and H. Mori, JAOCS., 1989, 66 (5), 664

22 A. Kuckzumow, P. Chevallier, P. Dillmann, P. Wajnberg and M. Rudas, Spectrochim. Acta B, 2000, 55, 1623.

23 M. Müller, C. Riekel, R. Vuong and H. Chanzy, Polymer, 2000, 41, 2627.

8024 T. Nakano, K. Kaibara, Y. Tabata, N. Nagata, S. Enomoto, K. Marukawa and Y. Umakoshi, Bone, 2002, 31 (4), 479.

25 S. R. Stock, J. Barss, T. Dahl, A. Veis and J. D. Almer, J. Struct. Biol., 2002, 139, 1.

26 O. Paris and M. Müller, Nucl. Instrum. Meth. B, 2003, 200, 390.

8527 M. Drakopoulos, P. M. Sergienko, I. Snigireva, A. Snigirev and A. A. Vazina, Nucl. Instrum. Meth. A, 2005, 543, 161.

28 Y. Kajiura, S. Watanabe, T. Itou, K. Nakamura, A. Iida, K. Inoue, N. Yagi, Y. Shinohara and Y. Amemiya, J. Struct. Biol., 2006, 155, 438.

29 P. Fratzl and R. Weinkamer, Prog. Mater. Sci., 2007, 52, 1263.

9030 R. Seidel, A. Gourrier, M. Burghammer, C. Riekel, G. Jeronimidis and O. Paris, Micron., 2008, 39, 198.

31 N. Yagi, N. Ohta and T. Matsuo, Int. J. Biol. Macromol., 2009, 45, 86.

32 H. Chanzy, J-L. Putaux, D. Dupeyre, R. Davies, M. Burghammer, S. Montanari and C. Riekel, J. Struct. Biol., 2006, 154, 100.

33 C. Riekel, R. J. Davies, Curr. Opin. Colloid Int., 2005, 9, 396.

34 T. Kikuzuki, Y. Shinohara, Y. Nozue, I. Kazuki and Y. Amemiya, Polymer, 2010, 51, 1632.

35 H. Kajioka, S. Yoshimoto, R. C. Gosh, K. Taguchi, S. Tanaka and A. Toda, Polymer, 2010, 51, 1837.

36 C. Riekel, P. Bösecke, O. Diat and P. Engström, J. Mol. Struct., 1996, 383, 291

37 Y. Shinohara, T. Takamizawa, S. Ueno, K. Sato, I. Kobayashi, M. Nakajima and Y. Amemiya, Cryst. Growth Des., 2008, 8 (9), 3123.

10538 S. Arima, S. Ueno, A. Ogawa and K. Sato, Langmuir, 2009, 25 (17), 9777.

39 L. Tanaka, K. Tanaka, S. Yamato, S. Ueno and K. Sato, Food Biophys., 2009, 4, 331.

40 D. Aquilano and G. Squaldino, in Crystallization Processes in Fats and Lipid Systems, ed. N. Garti and K. Sato, Marcel Dekker, New York, USA, 2001, pp. 1-51.

41 L. Bayés-García, T. Calvet, M. A. Cuevas-Diarte, S. Ueno and K. Sato, CrystEngComm., 2011, 13, 3592. 